\title{
Antimicrobial Susceptibility Profiles and Prevalence of ESBLS among Escherichia coli Isolates Recovered from Clinical Specimens in Different Services
}

\author{
Tuğba Cebeci ${ }^{1}$ Dilek Keskin ${ }^{2}$ Ahmet Ali Gökal ${ }^{3}$ \\ ${ }^{1}$ Giresun University, Espiye Vocational High School, Department of Medical Services and Techniques, Giresun, Turkey \\ ${ }^{2}$ Adnan Menderes University, Kosk Vocational High School, Department of Food Processing, Aydın, Turkey \\ ${ }^{3}$ Private Giresun Ada Hospital, Department of Infectious Diseases and Clinical Microbiology, Giresun Turkey
}

Received: 27 May 2019, Accepted: 11 July 2019, Published online: 31 December 2019

(C) Ordu University Institute of Health Sciences, Turkey, 2019

\begin{abstract}
Objective: A retrospective analysis of the widely used antibiotics all susceptibility testing results from Escherichia coli cultured from clinical specimens private hospital from (January 2016 to November 2018) was performed.

Methods: The VITEK 2 Compact automated microbiology system is designed for automated rapid antimicrobial susceptibility testing and identification of clinically relevant bacteria. Minimum inhibitory concentration (MIC) results previously obtained in recent clinical isolates with well-defined in isolates with well-characterized resistance mechanisms with the microdilution method were re-interpreted for the susceptible, intermediate and resistant categories using the 2018 EUCAST breakpoints. Clinical samples are most commonly isolated from blood, sputum and urine samples.

Results: Escherichia coli isolates were highly resistant to ampicillin, cefuroxime and cefixime $79,16 \%$, $60,41 \%$ and $58,33 \%$ respectively. Resistance rate of ceftriaxon was showed in 52,08\%. When we compared to resistance of trimethoprim/sulfamethoxazole, Escherichia coli isolates showed 51,04\% resistance rate. When it comes to the most sensitive antibiotics, sensitivity rate of fosfomycin, nitrofurantoin, ertapenem, imipenem, meropenem, gentamicin, and amikacin were $89,58 \% ; 91,66 \% ; 93,75 \% ; 93,75 \% ; 94,79 \%$; $83,33 \% ; 84,37 \%$ respectively.
\end{abstract}

Conclusion: Considering the antibiogram, fosfomycin, nitrofurantoin, ertapenem, imipenem, meropenem, gentamicin and amikacin should be preferred drugs for $E$. coli infection isolated from clinical samples.

Key words: $E$. coli, antibiotic sensitivity, clinical specimens

Suggested Citation: Cebeci T, Keskin D, Gökal A. Antimicrobial Susceptibility Profiles and Prevalence of ESBLS among Escherichia coli Isolates Recovered from Clinical Specimens in Different Services Middle Black Sea Journal of Health Science, 2019;5(3):186

Address for correspondence/reprints:

Tuğba Cebeci

Telephone number: +90 (454) $3101430 / 6481$

E-mail: tgbcbcdmn@gmail.com

DOI: $10.19127 / \mathrm{mbsjohs} .570826$

\section{Introduction}

Escherichia coli (E. coli), a gram-negative bacteria normally residing in the intestinal tract, is among the most common pathogenic agents in humans and animals. It is classified into various pathotypes, causing in-testinal and extra-intestinal infections (Hammerum and Heuer, 2009). E. coli has shown an increasing in antimicrobial resistance to most antibiotics was isolated from human (Sherley et al., 2004). The $\beta$-lactam antibiotics including penicillins, cephalosporins, carbapenem 
may act at several stages to prevent peptidoglycan synthesis (Jones et al., 2000). The incidence of infections caused by Enterobacteriaceae producing extended-spectrum beta lactamase (ESBL) has increased rapidly in the last 5 to10 years, mainly attributed to the successful distribution of CTX-M enzymes among $E$. coli causing urinary tract and bacteremic infections (Kang et al., 2012).

The aim of this study was to determine the characteristics and patterns of antibiotic resistance among isolates of $E$. coli recovered from clinical specimens in Giresun province.

\section{Methods}

\section{Bacterial isolates}

The ninety-six E. coli were isolated from clinical specimens from different services in private hospital. Bacterial isolates were identified and then commonly used for AST (Antimicrobial Susceptibility Testing) in clinical laboratories will therefore have to incorporate these criteria in their instruments to meet the needs of European microbiology laboratories according to standard methods described by (Cappuccino and Sherman, 2004). All isolates were obtained from patients at intensive care units. In total, ninety-six E. coli were isolated from various clinical samples and detected by the VITEK 2 (bioMérieux) at the microbiology laboratory of our hospital between from January in 2016 to December in 2018 (Ling et al., 2001). The data obtained were evaluated as numbers and percentages. Comments were made accordingly. It has taken the necessary permission from the outhorities.

\section{Antibiogram profile of E. coli}

Minimum Inhibitory Concentration (MIC) results previously obtained in recent clinical isolates with well-defined in isolates with wellcharacterized resistance mechanisms with microdilution method were re-interpreted using the 2018 EUCAST breakpoints. Fifteen different antibiotics were used. Antibiotics tested in ASTN327 (bioMérieux) card included ampicillin (AM), tazobactam/piperacillin (TPZ), cefuroxime (CXM), cefixime (CFM), ceftazidime (CAZ), ceftriaxone (CRO), ertapenem (ETP), imipenem (IMI), meropenem (MEM), amikacin (AK), gentamicin (GN), ciprofloxacin (CIP), fosfomycin (FOS), nitrofurantoin $(\mathrm{F})$, trimethoprim-sulfamethoxazole (SXT).

\section{Detection of ESBL}

VITEK 2 system with the antimicrobial susceptibility extend card AST-N327 (bioMérieux) card was designed to perform both screening and confirmatory tests for phenotypic detection of ESBL on the same plate. The use of several antimicrobial agents increases the sensitivity of ESBL detection (Sorlózano et. al., 2005).

\section{Multiple Antibiotic Resistance (MAR) index}

MAR index values were tested for according to (Matyar et al., 2008).

\section{Results}

The results of resistance pattern of E. coli isolates in our locality to antimicrobial agents showed that the ninety-six E. coli strains tested against fifteen antimicrobial agents in Table 1. E. coli isolates were highly resistant to AM, CXM and CFM $79,16 \%, 60,41 \%$ and $58,33 \%$ respectively. Resistance rate of CRO was showed in $52,08 \%$. When we compared to resistance of SXT, E. coli isolates showed $48,95 \%$ resistance rate. When it comes to the most sensitive antibiotics, sensitivity rate of FOS, F, ETP, IMI, MEM, GN and AK were $89,58 \%$; 91,66\%; 93,75\%; 93,75\%; 94,79\%; $83,33 \% ; 84,37 \%$ respectively as is illustrated in Table 1. Table 2 shows the antimicrobial susceptibility of all $E$. coli isolated from urine, blood, and sputum. Of the total E. coli isolates, 50 (\%52) isolates were ESBL producers and 46 (48\%) isolates were non-ESBL producers in Table 2.

\section{Discussion}

In our study, when we compared to resistance of AM, E. coli isolates showed high antibiotic resistance with $79,16 \%$ AM. Some researchers have reported resistance rate AM from $88,4 \%$ to $16,5 \%$ to E. coli in clinical samples (Tadesse et al., 2012; Niranjan and Malini., 2014). Our results were similar to Weissman et al. (2015) who also reported that AM resistance rate of E. coli $78 \%$.

The result of resistance CXM rate, E. coli isolates showed high antibiotic resistance with 60,41\% CXM. Previous researchers have reported resistance rate CXM from $100 \%$ to $60 \%$ to E. coli in clinical samples (Ugwu et al., 2017; Cheema et al., 2018).

In this study, resistance rate of CFM, E. coli isolates showed high antibiotic resistance with $58,33 \%$ CFM. Some researchers have reported resistance rate CFM from $94 \%$ to $40 \%$ to $E$. coli in clinical samples (Sah et al., 2016; Tasleem et al., 2018). Our results were like Cheema et al.,2018 


\section{Escherichia coli and Clinical Specimens in Different Service}

who also reported that CFM resistance rate of E. coli $61 \%$.
The resistance rate of CRO showed 52,08\%. Many researchers were reported that resistance rate

Table 1. Antibiotic suspectibility pattern of ninety-six E. coli isolated from urine, sputum and blood samples

\begin{tabular}{|c|c|c|c|}
\hline Antibiotics & Resistance & Intermediate & Sensitive \\
\hline$\overline{\mathbf{A M}}$ & $76(79,16 \%)$ & - & $20(20,83 \%)$ \\
\hline CXM & $58(60,41 \%)$ & - & $38(39,58 \%)$ \\
\hline CFM & $56(58,33 \%)$ & - & $40(41,66 \%)$ \\
\hline CRO & $50(52,08 \%)$ & $3(3,12 \%)$ & $43(44,79 \%)$ \\
\hline SXT & $47(48,95 \%)$ & - & $49(\% 51,04)$ \\
\hline CAZ & $43(44,79 \%)$ & $8(8,33 \%)$ & $45(46,87 \%)$ \\
\hline CIP & $40(41,66 \%)$ & $2(2,08 \%)$ & $54(56,25 \%)$ \\
\hline TPZ & $23(23,95 \%)$ & $22(22,91 \%)$ & $51(53,12 \%)$ \\
\hline GN & $14(14,58 \%)$ & $2(2,08 \%)$ & $80(83,33 \%)$ \\
\hline FOS & $10(10,41 \%)$ & - & $86(89,58 \%)$ \\
\hline $\mathbf{F}$ & $8(8,33 \%)$ & - & $88(91,66 \%)$ \\
\hline ETP & $6(6,25 \%)$ & - & $90(93,75 \%)$ \\
\hline IMI & $2(2,08 \%)$ & $4(4,16 \%)$ & $90(93,75 \%)$ \\
\hline MEM & $2(2,08 \%)$ & $3(3,12 \%)$ & $91(94,79 \%)$ \\
\hline AK & $2(2,08 \%)$ & $14(14,58 \%)$ & $80(83,33 \%)$ \\
\hline
\end{tabular}

Abrevations; AM, Ampicillin, CXM, Cefuroxime; CFM, Cefixime, CRO, Ceftriaxon SXT; Trimethoprim sulfamethoxazole, CAZ; Ceftazidim, CIP; Ciprofloxacin, TPZ; Piperacilin-Tazobactam, GN; Gentamicin, FOS, Fosfomycin, F; Nitrofurantoin, ETP, Ertapenem; IMI; Imipenem; MEM; Meropenem, AK; Amikacin

Table 2: Distribution of ninety-six E. coli clinical samples, sexuality, source, MAR Index and ESBL Producers

\begin{tabular}{|c|c|c|c|c|c|}
\hline Name of Clinic & $\begin{array}{l}\text { Number } \\
\text { of } \\
\text { samples }\end{array}$ & $\begin{array}{c}\text { Source of } \\
\text { isolates }\end{array}$ & $\begin{array}{c}\text { Sexuality } \\
\text { F/M }\end{array}$ & $\begin{array}{c}\text { ESBL } \\
\text { Producers }\end{array}$ & MAR İndex \\
\hline Infectious Diseases & 49 & Urine & $35 \mathrm{~F} / 14 \mathrm{M}$ & $30 \mathrm{P} / 19 \mathrm{~N}$ & $\begin{array}{l}\text { 0(7isl);0,07(4isl);0,13(2isl);0.2(3isl);0,27(5isl);0, } \\
\text { 53(3isl);0,33(4isl);0,6(3isl);0,8;0,47(8isl); } \\
0,4(6 \text { isl);0,67(3isl);0.87 }\end{array}$ \\
\hline Internal medicine & 11 & Urine & $7 \mathrm{~F} / 4 \mathrm{M}$ & $4 \mathrm{P} / 7 \mathrm{~N}$ & $\begin{array}{l}0 ; \quad 0,2 ; 0,07(2 \text { isl }) ; \quad 0,13(2 \text { isl); } 0,47(3 \text { isl }) ; \\
0,53(2 \text { isl }) ;\end{array}$ \\
\hline $\begin{array}{l}\text { Child Health and } \\
\text { Diseases }\end{array}$ & 12 & Urine & $4 \mathrm{~F} / 8 \mathrm{M}$ & $3 \mathrm{P} / 9 \mathrm{~N}$ & $\begin{array}{l}\text { 0(2isl); } 0,07(2 \text { isl }) ; 0,13(2 \text { isl }) ; 0,2(2 \text { isl }) ; 0,4(2 \text { isl }) ; \\
0,53 ; 0,47\end{array}$ \\
\hline Urology & 6 & Urine & $2 \mathrm{~F} / 4 \mathrm{M}$ & $4 \mathrm{P} / 2 \mathrm{~N}$ & $0,07(2$ isl $) ; 0,53(2$ isl $) ; 0,47 ; 0,4$ \\
\hline Chest Diseases & 7 & $\begin{array}{l}5 \text { Sputum } \\
\text { 1Urine } \\
\text { 1Blood }\end{array}$ & $3 \mathrm{~F} / 4 \mathrm{M}$ & $6 \mathrm{P} / 1 \mathrm{~N}$ & $0,47,0,53$ (3isl); 0,33(2isl); 0,27 \\
\hline $\begin{array}{l}\text { Anesthesia and } \\
\text { Reanimation }\end{array}$ & 2 & Urine & $2 \mathrm{M}$ & $1 \mathrm{P} / 1 \mathrm{~N}$ & 0,$07 ; 0,047$ \\
\hline $\begin{array}{l}\text { Physical Medicine } \\
\text { and Rehabilitation }\end{array}$ & 1 & Urine & $1 \mathrm{~F}$ & $1 \mathrm{~N}$ & 0,13 \\
\hline Gynocology & 1 & Urine & $1 \mathrm{~F}$ & $1 \mathrm{~N}$ & 0 \\
\hline Cardiology & 3 & $\begin{array}{l}\text { 1Blood } \\
\text { 2Urine }\end{array}$ & $2 \mathrm{~F} / 1 \mathrm{M}$ & $2 \mathrm{~N}$ & $0,0,33 ; 0,93$ \\
\hline Norologia & 1 & Urine & $1 \mathrm{M}$ & $1 \mathrm{~N}$ & 0 \\
\hline Pediatric Surgery & 1 & Urine & $1 \mathrm{~F}$ & $1 \mathrm{~N}$ & 0,13 \\
\hline Total & 96 & $\begin{array}{l}89 \text { Urine, } \\
5 \text { Sputum, } \\
2 \text { Blood }\end{array}$ & & $\begin{array}{l}50 \mathrm{P}(\% 52) \\
46 \mathrm{~N}(\% 48)\end{array}$ & $\begin{array}{l}63(66 \%) \geq 0.2 \\
33(34 \%)<0.2\end{array}$ \\
\hline
\end{tabular}

MAR, Multiple Antibiotic Resistance Index, isl; 1solates, +; ESBL Producing-; Non-ESBL Producing F; Female, M; Male 
of CRO varied from $41.6 \%$ to $91.8 \%$ (Park et al.,2012; Ayatollahi et al.,2013). Our results were higher than Ayatollahi et al. (2013) who also reported that CRO resistance rate of E. coli $41,6 \%$.

In our study, when we compared to resistance of SXT, E. coli isolates showed high antibiotic resistance with $48,95 \%$ SXT. In the previous researchers have reported resistance rate SXT from $34 \%$ to $16,1 \%$ to $E$. coli in clinical samples (Karlowsky et al., 2002; Guneysel et al., 2009).

When it comes to the most sensitive antibiotics, sensitivity rate of FOS, F, ETP, IMI, MEM, GN and AK were 89,58\%; 91,66\%; 93,75\%; 93,75\%; $94,79 \% ; 83,33 \% ; 84,37 \%$ respectively. Some researchers have reported sensitive rate FOS from $100 \%$ to $86 \%$ to E. coli in clinical samples (Ayub et al., 2016; Lawhale and Naikwade., 2017; Wagle et al., 2018).

Our results were similar to Ouizdi et al. (2018) who also reported that FOS sensitivity rate of $E$. coli $92 \%$. Some researchers have reported sensitive rate F from $100 \%$ to $86 \%$ to E. coli in clinical samples (Lawhale and Naikwade, 2017; Ouizdi et al., 2018). Our results were similar to Ouizdi et al. (2018) who also reported that $\mathrm{F}$ sensitivity rate of E. coli $92 \%$. Naber et al., (2010) repoprted that a positive urine culture was found in $74.6 \%$, and E. coli was most frequent $(76.7 \%)$ with the highest rate of susceptibility to fosfomycin $(98.1 \%)$. Similar findings of high susceptibility to nitrofurantoin and fosfomycin shown by Gupta et al. (2013), Fajfr et al. (2017) which is supportive to this study (Gupta et al., 2013; Dash et al., 2013; Fajfr et al., 2017).

The sensitivity rate of TPZ was $53,12 \%$. In previous researchers have reported sensitive rate TPZ from $57.9 \%$ to $9.2 \%$ to E. coli in clinical samples (Ghafur et al.,2012; Rugini et al.,2015). Our results were similar to Ghafur et al.,2012 who also reported that TPZ resistance rate of E. coli $57.9 \%$.

The susceptibility rate of ertapenem from $97.6 \%$ to $100 \%$ in different countries like Turkey, Estonia, Latvia, Lithuania, Portugal, Romania, Switzerland. and UK (Hawser et al., 2012). Many researchers have reported sensitivity rate ETP from $100 \%$ to $14,8 \%$ to $E$. coli in clinical samples (Malhotra et al., 2016; Devrim et al., 2018).

Unlike our study, no resistance to IMI was observed by Al-salamy (2012), Malhotra et al. (2016). Some researchers have reported that MEM sensitivity rate to $E$. coli in clinical samples (Mulla et al.,2011; Fernando et al.,2017).

Many researchers reported ESBL activity in $E$. coli strains, Albayrak and Kaya (2009), Eryilmaz et al. (2010) and Mumcuoglu et al. (2004) 19\%, 20\% and 6\% respectively. Guducuoglu et al. (2007) reported the samples according to the origin as policlinics or clinics and showed the ESBL activity as $18 \%$ and $47 \%$ respectively in E. coli strains.

In the present study, $63(64 \%)$ of the isolates showed Multiple Antibiotic Resistance three to fourteen antibiotics. All of the isolates showed resistance to at least one antibiotic. Malhotra et al. (2016) reported that out of 41 MDR isolates, maximum numbers of MDR strains were from urine (43.9\%) followed by pus $(41.5 \%)$, blood $(8.3 \%)$, fluid (5.6\%) and sputum (2.8\%) samples (Malhotra et al., 2016). Niranjan \& Malini also observed that majority of E. coli isolates (76.5\%) from urine samples were multidrug resistant like ours.

\section{Conclusion}

In this study, it has been shown that $E$. coli in different clinical specimens have experienced high resistance to AM, CXM, CFM and CRO. Some antibiotics show low resistance such as IMI, MEM and AK. An effective national and state level antibiotic policy should be framed for preserving the effectiveness of antibiotics and prevent the emergence of resistance.

Ethics Committee Approval: Patients' consent was obtained in the use of microbiological data.

Peer-review: Externally peer-reviewed.

Author Contributions: Concept -T.C., D.K.;DesignT.C, D.K; Supervision A.A.G; Materials- A.A.G; Data Collection and/or Processing- A.A.G.; Analysis and/or Interpretation- T.C., D.K.; Literature Review - T.C., D.K., A.A.G; Writing - T.C, D.K. ; Critical Review T.C., D.K., A.A.G.

Conflict of Interest: No conflict of interest was declared by the authors.

Financial Disclosure: The authors declared that this study has not received no financial support.

\section{References}

Albayrak N, Kaya S. Extended spectrum beta lactamases production and antimicrobial resistance ratio of Escherichia coli and Klebsiella pneumoniae strains isolated from various clinical samples. Turk Mikrobiyol Cem Derg. 2009; 39(1-2):16-21. 
Al-salamy AK. Detection of extended spectrumbeta lactamase enzymes producing $E$. coli that isolated from urine. Kufa Journal for Veterinary Medical Sciences 2012; 3(1):55-66.

Ayatollahi J, Shahcheraghi SH, Akhondi R, Soluti S. Antibiotic Resistance Patterns of Escherichia coli Isolated from Children in Shahid Sadoughi Hospital of Yazd. Iran J Ped Hematol Oncol. 2013; 3(2):78-82.

Ayub M, Amir JS, Firdous K. E. coli the Most Prevalent Causative Agent Urinary Tract Infection in Pregnancy: Comparative Analysis of Susceptibility and Resistance Pattern of Antimicrobials. Arch Clin Microbiol. 2016; 7:4. doi:10.4172/1989-8436.100054.

Cappuccino JG, Sherman N. Microbiology: A Laboratory Manual. 7th Edn. Pearson Education (Singapore) 2004, Indian Branch, New Delhi, ISBN: 080532836X. pp: 544.

Cheema, UK, Saleem S, Chaudary MA. Isolation and Antimicrobial Susceptibility Profile of Microorganisms Isolated from Ventilator Associated Pneumonia Patients. J Infec Dis Treat 2018; 4(1):3. doi:10.21767/24721093.100041

Dash M, Padhi S, Mohanty I, Panda P, Parida B. Antimicrobial resistance in pathogens causing urinary tract infections in a rural community of Odisha, India J Family Community Med. 2013; 20(1):20-6.

Devrim F, Serdaroğlu E, Çağlar İ, Oruç Y, Demiray $\mathrm{N}$, Bayram N, et al. The emerging resistance in nosocomial urinary tract infections: From the pediatrics perspective. Mediterr J Hematol Infect Dis 2018; 10:1-5.

Eryilmaz M, Bozkurt ME, Yildiz MM, Akın A. Investigation of the prevalance of extended spectrum beta lactamase producing Escherichia coli strains isolated from various clinical samples. Marmara Ecza Derg 2010; 14:10-12.

Fajfr M, Louda M, Paterova P, Ryskova L, Pakovsky J, Kosina J. The susceptibility to fosfomycin of Gram-negative bacteria isolates from urinary tract infection in the Czech Republic: data from a unicentric study. BMC Urol. 2017; 17:33.

Fernando MMPSC, Luke WANV, Miththinda JKND, Wickramasinghe RDSS, Sebastiampillai BS, Gunathilake MPML, Silva Premaratna R. Extended spectrum beta lactamase producing organisms causing urinary tract infections in Sri Lanka and their antibiotic susceptibility pattern -A hospital based cross sectional study. BMC Infectious Diseases 2017; 17(1):1.
Ghafur A, Ramasamy P, Sarathy N, Krishnamurthy R, Durairajan S. Sensitivity pattern of Gramnegative bacteria to the new $\beta$-lactam/ $\beta$ lactamase inhibitor combination: Cefepime/tazobactam. J Microbiol Infect Dis. 2012; 2(1):5-8.

Guducuoglu H, Baykal S, Izci H, Berktaş M. Antimicrobial resistance of Escherichia coli and Klebsiella pneumoniae strains that produce extended spectrum beta lactamase. ANKEM Derg 2007; 21(3):155-60.

Guneysel O, Onur O, Erdede M, Denizbasi A. Trimethoprim/sulfamethoxazole resistance in urinary tract infections. J Emerg Med. 2009; 36:338-41. doi: 10.1016/j.

Gupta V, Rani H, Singla N, Kaisha N, Chander J. Determination of extended-spectrum- $\beta$ Lactamases and AmpC production in uropathogenic isolates of Escherichia coli and susceptibility to Fosfomycin. Lab Physicians. 2013; 5(2):90-3.

Jones RN, Jenkins SG, Hoban DJ, Pfaller MA, Ramphal R. In vitro efficacy of six cephalosporins tested against Enterobacteriaceae isolated at 38 North American medical centres participating in the SENTRY Antimicrobial Surveillance Program, 1997-1998. Int. J. Antimicrob. Agents., 2000; 15: 111-118.

Hammerum AM, Heuer Ole E. Human Health Hazards from Antimicrobial-Resistant Escherichia coli of Animal Origin, Clinical Infectious Diseases 2009; 48(7): 916-921.

Hawser SP, Bouchillon SK, Lascols C, Hackel M, Hoban DJ, Badal RE, Cantón R. Susceptibility of European Escherichia coli clinical isolates from intra-abdominal infections, extendedspectrum $\beta$-lactamase occurrence, resistance distribution, and molecular characterization of ertapenem-resistant isolates (SMART 20082009). Clin Microbiol Infect. 2012; 18(3):253-9.

Kang CI, Wi YM, Lee MY, Ko KS, Chung DR, Peck KR. Epidemiology and risk factors of community onset infections caused by extendedspectrum beta-lactamase-producing Escherichia coli strains. J ClinMicrobiol 2012; 50:312-7.

Karlowsky JA. Trends in antimicrobial resistance among urinary tract infection isolates of Escherichia coli from female outpatients in the United States. Antimicrob Agents Chemother 2002; 46(8):2540-5. 
Lawhale MA, Naikwade R. Recent pattern of drug sensitivity of most commonly isolated uropathogens from Central India. Int J ResMed Sci 2017; 5:3631-6.

Ling TK, Tam PC, Liu ZK, Cheng AF. Evaluation of VITEK 2 rapid identification and susceptibility testing system against gramnegative clinical isolates. J. Clin. Microbiol. 2001; 39: 2964-6.

Park YS, Adams-Haduch JM, Shutt KA, et al. Clinical and microbiologic characteristics of cephalosporin-resistant Escherichia coli at three centers in the United States. Antimicrob Agents Chemother. 2012;56(4):1870-1876. doi:10.1128/AAC.05650-11

Malhotra R, Sikka R, Chaudhary U. Antimicrobial sensitivity pattern among clinical isolates of Escherichia coli in tertiary care centre of Northern India. Int J Res Med Sci 2016; 4:63942.

Matyar F, Kaya A, Dinçer S. Antibacterial agents and heavy metal resistance in Gram-negative bacteria isolated from seawater, shrimp and sediment in Iskenderun Bay, Turkey. Science Total and Environment 2000; 407: 279-285.

Mulla S, Charan J, Panvala T. Antibiotic sensitivity of Enterobacteriaceae at a tertiary care center in India. Chron Young Sci 2011; 2:214-8.

Mumcuoglu I. Investigation of extended spectrum beta-lactamase production and antimicrobial resistance in Escherichia, Klebsiella and Proteus strains. ANKEM Derg 2004; 18(1):9-11.

Naber GK, Schaeffer AJ, Heyns CF. Urogenital infections. Ed. 2010. European Association of Urology. -International Consultation on Urological Diseases.

Niranjan V, Malini A. Antimicrobial resistance pattern in Escherichia coli causing urinary tract infection among inpatients. Indian J Med Res. 2014; 139(6): 945-948.

Rugini CL, Sobottka AM, Fuentefria DB (2015) Occurrence and sensitivity profile of extended spectrum beta-lactamase-producing Enterobacteriaceae at a tertiary hospital in Southern Brazil. Rev. Soc. Bras. Med. Trop. doi: 10.1590/0037-8682-0211-2015.
Sah SK, Regmi S, Upreti AR, Pathak S. Antibiotic resistance patterns and evaluation of treatment in out-patients with urinary tract infections in Nepal. Int J Pharm Sci Res 2016; 7(11): 462631.

Sherley M, Gordon DM, Collignon PJ. Evolution of multi-resistance plasmids in Australian clinical isolates of Escherichia coli. Microbiology 2004; 150: 1539-1546.

Sorlózano A, Gutiérrez J, Piédrola G, Soto MJ. Acceptable performance of VITEK 2 system to detect extended-spectrum beta-lactamases in clinical isolates of Escherichia coli: a comparative study of phenotypic commercial methods and NCCLS guidelines. Diagn Microbiol Infect Dis 2005;51:191-3.

Tasleem S, Sana S, Syed BN. Sensitivity Pattern of Staphylococcus aureus and Escherichia coli Against Cefaclor and Cefixime. CPQ Medicine 2018; 5(2), 1-6.

Tadesse DA, Zhao S, Tong, E, Ayers S, Singh A, Bartholomew MJ. Antimicrobial Drug Resistance in Escherichia coli from Humans and Food Animals, United States, 1950-2002. Emerg Infect Dis. 2012; 18(5):741-749. https://dx.doi.org/10.3201/eid1805.111153.

Ugwu MC, Edeani GI, Ejikeugwu CP, Okezie U, Ejiofor SO. Antibiotic Susceptibility Profile of Escherichia coli and Salmonella Causing Childhood Diarrhoea in Awka Municipality, South-eastern Nigeria. Clin Microbiol 2017; 6: 277. doi:10.4172/2327-5073.1000277.

Ouzdi ZA, Lamiae Arsalane, Youssef El kamouni, Said Zouhair. The Resistance of Uropathogenic Bacteria to Fosfomycin. Pathology and Laboratory Medicine. 2018; 2(2): 47-50.

Wagle S, Khanal BR, Tiwari BR. High Susceptibility of Fosfomycin to Uropathogenic Escherichia coli Isolated at Tertiary Care Hospital of Nepal. JAMB 2018; 13(2): 1-8.

Weissman SJ, Hansen NI, Zaterka-Baxter K, Higgins RD, Stoll BJ. Emergence of Antibiotic Resistance-Associated Clones Among Escherichia coli Recovered from Newborns with Early-Onset Sepsis and Meningitis in the United States, 2008-2009. Journal of the Pediatric Infectious Diseases Society, 2016; 5(3):269-76. 